\title{
On Self and Other
}

\author{
Xuejiao Li \\ University of Kassel \\ Huili Wang, Zhongliang Cui \\ Dalian University of Technology
}

\begin{abstract}
In the philosophy of mind, the essential qualities of self and selfhood have been discussed widely. According to Zahavi $(2015,149)$, "the notion of an experiential self is the precondition of any plausible account of intersubjectivity." In Zahavi (2015), he elaborates two influential views on selfhood and offers a phenomenological perspective from which he argues that selfhood is both a built-in feature of experience and socially constructed. In the following paper, we would further investigate the essential qualities of self in the line with Zahavi (2015) and provide a complementary quality of self from a phenomenological view, namely, the predictability of the expressive phenomena of subjects. We would also explore the intersubjective relationship between others and self and discuss the sharing phenomenon of empathy.
\end{abstract}

Keywords: self, selfhood, other, phenomenology, intersubjectivity, empathy

\section{Introduction}

As the Ancient Greek aphorism said, "know thyself." How to define the notion of self? What is a self and what is not? Such questions have been discussed widely for long since the very beginning of the philosophical thinking. The essential qualities of self have been a problem that haunts the philosophers and there is still no philosophical consensus concerning the nature of self (Gallagher and Zahavi 2012, 197). Concerning the notion of selfhood, there are two to-some-extent satisfactory approaches. Experientialist holds that selfhood is "a built-in feature our experiential life" and its claim accounts to a primitive form of selfhood according to which the experiences are first-personal and for me (Zahavi 2015, 145). According to the second approach, however, a self is something we achieve rather than we are given. Self emerges "in a process of social experience and interchange" and hence, self is more of a social construction (2015, 145). As Zahavi (2015) said, both approaches provide convincing refutations of other radical definitions of self, such as the one proposed by anti-realist Metzinger, who argues that self is "an unchanging and ontologically independent entity" and also the no-self view, narrativists and phenomenal externalists (Zahavi 2017a, 193). However, Zahavi (2015) aims to combine these two approaches and presents his argumentation based on a theoretical frame of phenomenology, arguing that "we should not accept being forced to choose between viewing selfhood as either

Xuejiao Li, Master Graduate, Faculty of Humanities, University of Kassel, Germany; main research fields: Philosophy of Mind, Philosophy of Language, and Cognitive Science.

Huili Wang, Prof., Dr., Department of English, School of Foreign Languages, Dalian University of Technology, China; main research fields: Philosophy of Language and Cognitive Neurolinguistics.

Zhongliang Cui, Ph.D. candidate, Department of Philosophy, School of Humanities and Social Science, Dalian University of Technology, China; main research fields: Philosophy of Mind and Phenomenology. 
a socially constructed achievement or an innate and culturally invariant as a given" (147). In the following contribution, we focus on the notion of self and try to provide a more elaborated explanation of the essential qualities of selfhood. We would further explore the relationship between self and other and share our contemplation concerning the mental phenomena intersubjectively mediated, namely, empathy.

\section{Self}

The notion of self saw a disparity of conceptions, which is both problematic and productive and foreshadows diverse approaches in the studies of the self (Gallagher and Zahavi 2012, 198):

- Material self, social self, spiritual self (James 1890/1950).

- Ecological self, interpersonal self, extended self, private self, conceptual self (Neisser 1988).

- Autobiographical self, cognitive self, contextualized self, core self, dialogical self, embodied self, empirical self, fictional self, minimal self, neural self (Damasio 1999; Strawson 1999).

Nevertheless, all the terms of the self can be categorized into two dimensions of self, which are experiential and social, or, given and achieved.

Concerning the experiential dimension of the self, Damasio claims that a sense of self is an essential part of consciousness (Damasio 1999; Gallagher and Zahavi 2012, 202). Self is the first-personal subject that senses what $I$ am experiencing and have direct access to the perceptions aroused. This first-personal character of self is innate. For the infants, the sense of self will be gradually strengthened along with the developmental process and they will eventually discover the existence of boundaries between self and others (Zahavi 2015, 143). And this dimension of self has its phenomenological ancestry and can be seen along with Husserl, Sartre, and Henry (145).

Self as socially constructed develops its selfhood through social interactions and the infants perceive others as separate entities as an achievement in the process of interpersonal experience and transformed through social interactions. This approach to the self enables us to distinguish from being only sentient and being a self. According to this approach, "to be a self is to stand in a particular interpretative and evaluative relation to oneself, and the only way to obtain the reflexive self-relation constitutive of selfhood is by being socialized into a publicly shared space of normativity" (145).

Both built-in and socially constructed, there are still mechanisms of expressive phenomena of subjects and essential qualities of self which have been defined as implicit/explicit self. "The explicit self builds on declarative knowledge about one's individual mind (relying on conceptual knowledge about one's self as a particular person)" and therefore instructs the subject to behave in certain ways consciously whereas

the implicit self emerges from procedural knowledge for performing mental acts, taking the role of the center on which all of these acts converge (relying on non-conceptual experience of one's self as being involved in acts like perceiving, knowing, acting, etc.). The explicit self is usually seen to be shaped from without (i.e., by cultural, social, and biographical context) whereas the implicit self is seen to be shaped from within and emerge as part and parcel of an individual's natural endowment. (Prinz 2017, 3)

In speak of implicit and explicit natures of the self, we would like to propose another explanation, namely, the predictability of the expressive phenomenon of the first-personal or for-me subject. Along with the phenomenological approach to the self, expressive phenomenon accounts to the reflective consciousness of the self and this supports both the claims of the social constructivism of the self and the import theory of subjectivity and selfhood (Lazar 2001, 271). Concerning the predictability of our expressive behavior, we all 
have the experiences that some of our behaviors are planned or fall within our expectations whereas there are also other behaviors made by us which may shock us and are beyond our expectations even though we are the agents of the spoken words or actions. Some people even reported that their unexpected reactions under certain conditions have changed their knowledge of themselves afterwards. The unpredictability of expressive behavior appeals to us in the sense that we as the first-personal subjects also have limited access to all the mechanism of our conscious mind, what in some circumstances put us on the same level of the access of our mind with others. And the evidence from which we can draw to make certain unpredictable behaviors valid is not more sufficient for us than for the others. This category of unpredictable phenomenon of the subjects provides our insights concerning the problem of other minds since we have too a limited access to our own minds. Therefore, concerning the nature of the self, we can only recognize the essential qualities of the self and should not go radical to argue that the self is determined by certain factors and even argue that there is no self.

\section{Other: A Phenomenological Approach}

As experiential selves, it is straightforward for us to attribute the same subjective nature of self to others (Prinz 2017, 4) in that we perceive others as the experiencing entities with sensations. And by the standard argument which is the argument of analogy we can conclude that the others also have minds. In the light of the analogy argument, I begin by assuming the existence of my own mind and noting a correlation between my having a mind and my behavior. I then observe similar sorts of behavior in another, and conclude by analogy that the other also has a mind (Avramides 2001, 9). Phenomenology, a philosophical approach originated by Edmund Husserl, which bases its considerations on the way things are experience (Gallagher and Zahavi 2012, 5-6; Moran 2000, 1), provides us with an extension of the observational behavior. We regard the expressive phenomenon as clues and collect descriptions of the "interior perspective" of the experiencing conscious entities. And phenomenology as a "descriptive science of consciousness" renews and deepens our knowledge of the expressive phenomenon (Lohmar 2006, 9).

Intersubjectivity is a concept studied in various subjects such as philosophy, psychology, sociology, and psychoanalysis. It is a key concept in phenomenology and has gained significant attention in recent years. The concept of intersubjectivity describes the mode of interpersonal interactions between subjects (Lazar 2001, 278).

Phenomenological philosophers highlight the experiential dimension of interpersonal experiences (Stawarska 2006, 3). And according to Zahavi, the experiential dimension of self is the pre-condition of any plausible accounts of intersubjectivity (Zahavi 2014, 96; 2015, 149). The distinctive contribution of a phenomenology of intersubjectivity, according to Sartre (Zahavi 2014, 97), is its exploration of the ontological interdependence of self and other.

\section{Empathy}

Empathy has drawn significant attention from different disciplines among which are philosophy, cognitive science, psychology, and primatology. For phenomenolgists, empathy is testimony for our understanding of separate conscious entities. It entails our perceptions of the mental life of others in their expressive behaviors and utterances (Zahavi 2015, 8; 2017b, 39). According to Zahavi and Rochat (2015), "empathy is the experience of the embodied mind of the other, an experience which rather than eliminating the difference between self-experience and other-experience takes the asymmetry to be a necessary and persisting existential fact." Empathy allows me to experience other experiencing subjects (544). 
When speaking of the problem of other minds and intersubjectivity, for the inaccessibility of the first-personal subjects to others, some have argued that there is at initial stage an undifferentiated anonymous state from which the difference between the self and others is founded and derived. Zahavi (2015, 9-10) claims that this approach to the problem of other minds and intersubjectivity is not a "solution," instead, it dissolves the problem. On the contrary for phenomenologists, empathy endorses an experiential distinction between self and other and this distinction is inherent and also essential for understanding self and others.

\section{Conclusion}

Along with the phenomenological approach adopted by Zahavi to combine the two essential dimensions of the self, namely, experiential dimension and social-constructed dimension, we proposed a complementary quality concerning the expressive phenomenon of the self, namely, predictability. Based on the understanding of self, we go one step other and elaborate the separate entities experience by the self, others and discuss the notion of intersubjectivity and agree with the claim that the experiential self is the prerequisite for a solution of the problem of other minds. We finally discussed the concept of empathy as it presupposes the experiential distinction between self and other. Further elaborations will be followed on the predictability and unpredictability of the expressive behaviors of others and the constitution of "we."

\section{Works Cited}

Avramides, A. Other Minds. London: Routledge, 2001.

Gallagher, S. \& Zahavi, D. The Phenomenological Mind. 2nd ed. London: Routledge, 2012.

Lazar, Rina. "Subject in First Person—Subject in Third Person: Subject, Subjectivity, and Intersubjectivity." American Journal of Psychoanalysis 61.3 (2001): 271-91.

Lohmar, D. "Mirror Neurons and the Phenomenology of Intersubjectivity." Phenomenology \& the Cognitive Sciences 5.1 (2006): $5-16$.

Moran, D. Introduction to Phenomenology. London: Routledge, 2000.

Prinz, W. "Modeling Self on Others: An Import Theory of Subjectivity and Selfhood." Consciousness and Cognition. 2017. $<$ http://dx.doi.org/10.1016/j.concog.2017.01.020>.

Stawarska, B. "Introduction: Intersubjectivity and Embodiment." Phenomenology \& the Cognitive Sciences 5.1 (2006): 1-3.

Zahavi, D. "Self and Other: From Pure Ego to Co-constituted We." Continental Philosophy Review 48.2 (2015): 143-60.

---. "Thin, Thinner, Thinnest: Defining the Minimal Self." Eds. C. Durt, T. Fuchs, and C. Tewes. Embodiment, Enaction, and Culture: Investigating the Constitution of the Shared World (Chapter 9, 193-9). Cambridge, Mass.: MIT Press, 2017a.

---. "Phenomenology, Empathy, and Mindreading." Ed. H. L. Maibom. The Routledge Handbook of Philosophy of Empathy (Chapter 3, 33-43). London: Routledge, 2017b.

Zahavi, D. \& Rochat, P. "Empathy $\neq$ Sharing: Perspectives from Phenomenology and Developmental Psychology.” Consciousness and Cognition 36 (2015): 543-53.

Zahavi, D. \& Kriegel, U. "For-me-ness: What It Is and What It Is not." Eds. D. Dahlstrom, A. Elpidorou, and W. Hopp. Philosophy of Mind and Phenomenology: Conceptual and Empirical Approaches (Chapter 2, 36-53). New York: Routledge, (Routledge Research in Phenomenology, Vol. 2), 2016. 